
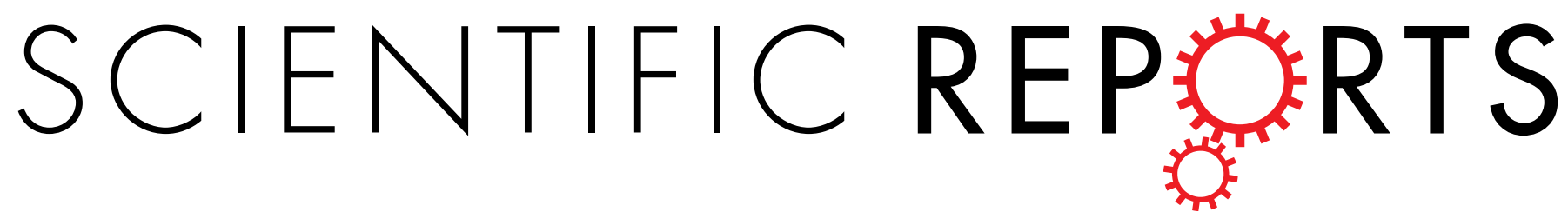

\title{
OPEN Short-term Effects of Outdoor Air Pollution on Lung Function among Female Non-smokers in China
}

Received: 07 June 2016

Accepted: 20 September 2016

Published: 13 October 2016

\author{
Yun Zhou ${ }^{1,2, *}$, Yuewei Liu ${ }^{3, *}$, Yuanchao Song ${ }^{1,2}$, Jungang Xie ${ }^{4}$, Xiuqing Cui ${ }^{1,2}$, Bing Zhang ${ }^{5}$, \\ Tingming $\mathrm{Sh}^{3}{ }^{3}$, Jing Yuan ${ }^{1,2}$ \& Weihong Chen ${ }^{1,2}$
}

Short-term exposures to outdoor air pollutants have been associated with lower lung function, but the results are inconsistence. The effects of different pollutant levels on lung function changes are still unclear. We quantified the effects of outdoor air pollution exposure $\left(\mathrm{NO}_{2}, \mathrm{PM}_{10}, \mathrm{O}_{3}\right.$, and $\left.\mathrm{PM}_{2.5}\right)$ on lung function among 1,694 female non-smokers from the Wuhan-Zhuhai Cohort in China by using linear mixed model. We further investigated the associations in the two cities with different air quality levels separately to quantify the effects of different pollutant level exposure on lung function. We found the moving averages of $\mathrm{NO}_{2}, \mathrm{PM}_{10}$, and $\mathrm{PM}_{2.5}$ concentrations were significantly associated with reduced FVC. In city at high pollutant level, the moving average of $\mathrm{NO}_{2}, \mathrm{PM}_{10}, \mathrm{O}_{3}$, and $\mathrm{PM}_{2.5}$ exposures were significantly associated with both $\mathrm{FVC}$ and $\mathrm{FEV}_{1}$ reductions. In the low-level air pollution city, $\mathrm{PM}_{10}$ (Lag03-Lag05) and $\mathrm{O}_{3}$ concentrations (Lag01-Lag03) were significantly associated with reduced FVC, while $\mathrm{PM}_{10}$ (Lag03-Lag05), $\mathrm{O}_{3}$ (Lag0-Lag03), and $\mathrm{PM}_{2.5}$ (Lag04-Lag06) exposure were significantly associated with reduced $\mathrm{FEV}_{1}$. Our results suggest that outdoor air pollution is associated with shortterm adverse effects on lung function among female non-smokers. The adverse effects may persist for longer durations within 7 days at higher air pollutant levels.

Air pollution has drawn much public health concern globally, especially in developing countries. In China, it was reported that annual mean concentrations of $\mathrm{PM}_{10}$ and $\mathrm{PM}_{2.5}$ in 2014 were $105 \mu \mathrm{g} / \mathrm{m}^{3}$ and $62 \mu \mathrm{g} / \mathrm{m}^{3}$ respectively, which were 5 to 6 times more than those recommended by the World Health Organization (WHO) air quality guidelines for $\mathrm{PM}_{10}\left(20 \mu \mathrm{g} / \mathrm{m}^{3}\right)$ and $\mathrm{PM}_{2.5}\left(10 \mu \mathrm{g} / \mathrm{m}^{3}\right)^{1,2}$. Outdoor air pollution including particulate matter $(\mathrm{PM})$, ozone $\left(\mathrm{O}_{3}\right)$ and nitrogen dioxide $\left(\mathrm{NO}_{2}\right)$ has been reported to be associated with short-term adverse effects on lung function in healthy adults, children, or patients with chronic obstructive pulmonary disease (COPD) or asthma ${ }^{3-8}$. However, most of these studies were conducted in populations in developed countries, where air pollutant levels were lower than developing countries (e.g. China). A few studies have examined the short-term effects of relatively high outdoor air pollutant level on lung function alteration among school children or college students $^{9-16}$, the effects of high air pollution level exposure is still unclear among adults. In addition, the association between air pollution and lung function is inconsistence. Some studies reported that the negative association could be weak or absent for longer moving average exposure ${ }^{3,17}$, while a Brazil study reported that a cumulative adverse effects on lung function ${ }^{16}$. Whether the effects of different pollutant levels on lung function are different is still unknown.

Another barrier to explore the association between air pollution and lung function is the existence of effect modifiers. One is cigarette smoking, which can lead to significant lung function decline through pulmonary

${ }^{1}$ Department of Occupational \& Environmental Health, School of Public Health, Tongji Medical College, Huazhong University of Science and Technology, Wuhan, Hubei 430030, China. ${ }^{2}$ Key Laboratory of Environment and Health, Ministry of Education \& Ministry of Environmental Protection, and State Key Laboratory of Environmental Health (Incubating), School of Public Health, Tongji Medical College, Huazhong University of Science and Technology, Wuhan, Hubei 430030, China. ${ }^{3}$ Hubei Provincial Key Laboratory for Applied Toxicology, Hubei Provincial Center for Disease Control and Prevention, Wuhan, Hubei 430079, China. ${ }^{4}$ Department of Respiratory and Critical Care Medicine, Tongji Hospital, Tongji Medical College, Huazhong University of Science and Technology, Wuhan, Hubei 430030, China. ${ }^{5}$ Department of Immunization Program, Zhejiang Provincial Center for Disease Control and Prevention, Hangzhou, Zhejiang 310051, China. ${ }^{*}$ These authors contributed equally to this work. Correspondence and requests for materials should be addressed to J.Y. (email: jyuan@tjh.tjmu.edu.cn) orW.C. (email: wchen@mails. tjmu.edu.cn) 


\begin{tabular}{|c|c|c|c|c|}
\hline Characteristics & Total & Wuhan & Zhuhai & $p$ value \\
\hline $\mathrm{N}(\%)$ & 1,694 & 1,177 & 517 & - \\
\hline Age, year $($ Mean \pm SD) & $56.0 \pm 12.0$ & $55.4 \pm 12.5$ & $57.2 \pm 10.6$ & 0.003 \\
\hline Height, cm (Mean \pm SD) & $153.7 \pm 5.7$ & $153.8 \pm 5.8$ & $153.4 \pm 5.7$ & 0.55 \\
\hline Body mass index, $\mathrm{kg} / \mathrm{m}^{2},($ Mean $\pm \mathrm{SD})$ & $24.8 \pm 3.6$ & $24.8 \pm 3.7$ & $24.6 \pm 3.4$ & 0.87 \\
\hline Passive smoking, $\mathrm{N}(\%)$ & & & & $<0.001$ \\
\hline No & $957(56.5)$ & $617(52.4)$ & $340(65.8)$ & - \\
\hline Yes & $737(43.5)$ & $560(47.6)$ & $177(34.2)$ & - \\
\hline Cooking, $\mathrm{N}(\%)$ & & & & 0.10 \\
\hline No & $246(14.5)$ & $182(15.5)$ & $64(12.4)$ & - \\
\hline Yes & $1448(85.5)$ & $995(84.5)$ & $453(87.6)$ & - \\
\hline Asthma, N (\%) & & & & 0.61 \\
\hline No & $1689(99.7)$ & $1173(99.7)$ & $516(99.8)$ & - \\
\hline Yes & $5(0.3)$ & $4(0.3)$ & $1(0.2)$ & - \\
\hline Heart disease ${ }^{\star}, \mathrm{N}(\%)$ & & & & 0.003 \\
\hline No & $1658(97.9)$ & $1160(98.6)$ & $498(96.3)$ & - \\
\hline Yes & $36(2.1)$ & $17(1.4)$ & $19(3.7)$ & - \\
\hline Physical activity, N (\%) & & & & $<0.001$ \\
\hline No & $725(42.8)$ & $566(48.1)$ & $159(30.8)$ & - \\
\hline Yes & $969(57.2)$ & $611(51.9)$ & $358(69.2)$ & - \\
\hline FVC, $\mathrm{ml}($ Mean \pm SD) & $2369.9 \pm 530.5$ & $2436.2 \pm 545.2$ & $2219.0 \pm 461.4$ & $<0.001$ \\
\hline $\mathrm{FEV}_{1}, \mathrm{ml}($ Mean $\pm \mathrm{SD})$ & $2006.1 \pm 462.1$ & $2026.1 \pm 471.3$ & $1960.7 \pm 437.5$ & 0.007 \\
\hline$\% \mathrm{FEV}_{1} / \mathrm{FVC}$ & $84.8 \pm 8.6$ & $83.3 \pm 8.6$ & $88.2 \pm 7.5$ & $<0.001$ \\
\hline
\end{tabular}

Table 1. Characteristics of all non-smoking females in Wuhan and Zhuhai $(\mathrm{N}=1,694)$. Abbreviations: FVC, forced vital capacity; $\mathrm{FEV}_{1}$, forced expiratory volume in 1 second; SD, standard deviation. ${ }^{*}$ The 10 th version of the International Classification of Diseases (ICD-10) was used to classify heart diseases (ICD-10 codes: I00-I09, I11, I13, and I20-I51).

oxidant stress, inflammation and tissue damage ${ }^{18}$. Another potential effect modifier is sex. Lung function levels among females are significantly lower than those among males due to lung development and physiology ${ }^{19}$. Both smoking and sex have been reported to modify the association between outdoor air pollutants and lung function, but the results remain inconsistent; a few studies surprisingly did not find the effect modification ${ }^{3,20,21}$. Nonetheless, it is necessary and important to identify the effect modification either by stratified analysis or by restricting study populations.

In this study, we investigated short-term effects (up to 7 days) of air pollutants $\left(\mathrm{NO}_{2}, \mathrm{PM}_{10}, \mathrm{O}_{3}\right.$, and $\left.\mathrm{PM}_{2.5}\right)$ on lung function among restricted to lifetime female non-smokers from the Wuhan-Zhuhai Cohort. We further examined the associations in the two study cities with different air quality levels separately to quantify the effects of different pollutant level exposures on lung function.

\section{Results}

Characteristics for the study participants are presented in Table 1. The mean age of all subjects was 56.0 years. There were no significant differences in height, BMI, cooking and asthma between participants from Wuhan and Zhuhai (all $p>0.05$ ). Percentage of passive smokers, FVC and $\mathrm{FEV}_{1}$ were significantly lower in Zhuhai city than those in Wuhan, while age, heart disease, physical activities, and $\mathrm{FEV}_{1} / \mathrm{FVC}$ were significantly higher in Zhuhai compared with those in Wuhan (all $p<0.05$ ). Air pollutant distributions and their Spearman correlation coefficients during the days before lung function test are given in Fig. 1, and Tables 2 and 3. The concentrations of $\mathrm{NO}_{2}$, $\mathrm{PM}_{10}, \mathrm{O}_{3}$, and $\mathrm{PM}_{2.5}$ in Zhuhai were lower than those in Wuhan. Pairwise correlations for each pair of the 4 air pollutants were significantly positive (all $p<0.01$ ). The positive correlations were found between $\mathrm{NO}_{2}$ and $\mathrm{PM}_{10}$, $\mathrm{NO}_{2}$ and $\mathrm{PM}_{2.5}$, and $\mathrm{PM}_{2.5}$ and $\mathrm{PM}_{10}$ in both Wuhan and Zhuhai (all $p<0.05$ ). $\mathrm{O}_{3}$ was positively correlated with $\mathrm{PM}_{10}$ in Zhuhai (Spearman correlation coefficient $\mathrm{r}=0.39, p=0.02$ ). Distributions and Spearman correlation coefficients for the different moving averages of pollutant exposures were shown in Supplementary Table S1. Positive correlations were observed between each pair of the moving averages of the 4 pollutants exposure (Lag0-Lag07) among all participants (All $p<0.01)$.

Figure 2 shows the associations between per $10 \mu \mathrm{g} / \mathrm{m}^{3}$ increase in all the pollutants concentrations for each moving average and lung function alteration using single models among all the 1,694 subjects. $\mathrm{NO}_{2}(\operatorname{Lag} 07), \mathrm{PM}_{10}$ (Lag03-Lag07) and $\mathrm{PM}_{2.5}$ (Lag02-Lag07) were significantly associated with decreased FVC, and no pollutant exposures were observed to be associated with $\mathrm{FEV}_{1}$. The significantly negative association between exposure to pollutants and lung function $\left(\mathrm{FVC}\right.$ and $\mathrm{FEV}_{1}$ ) were stronger for longer moving averages of exposures. We observed that negative effects of $\mathrm{NO}_{2}, \mathrm{PM}_{2.5}$ and $\mathrm{PM}_{10}$ on lung function become stronger for longer moving averages of exposures. The influence of air pollutants on FVC was stronger than those on $\mathrm{FEV}_{1}$. Furthermore, we also quantify the associations between each interquartile ranges-increase air pollutant exposures and lung function (See Supplementary Fig. S1) (IQRs for $\mathrm{NO}_{2}, \mathrm{PM}_{10}, \mathrm{O}_{3}$ and $\mathrm{PM}_{2.5}$ were 43.2, 94.8, 52.7 and 57.4, respectively). 


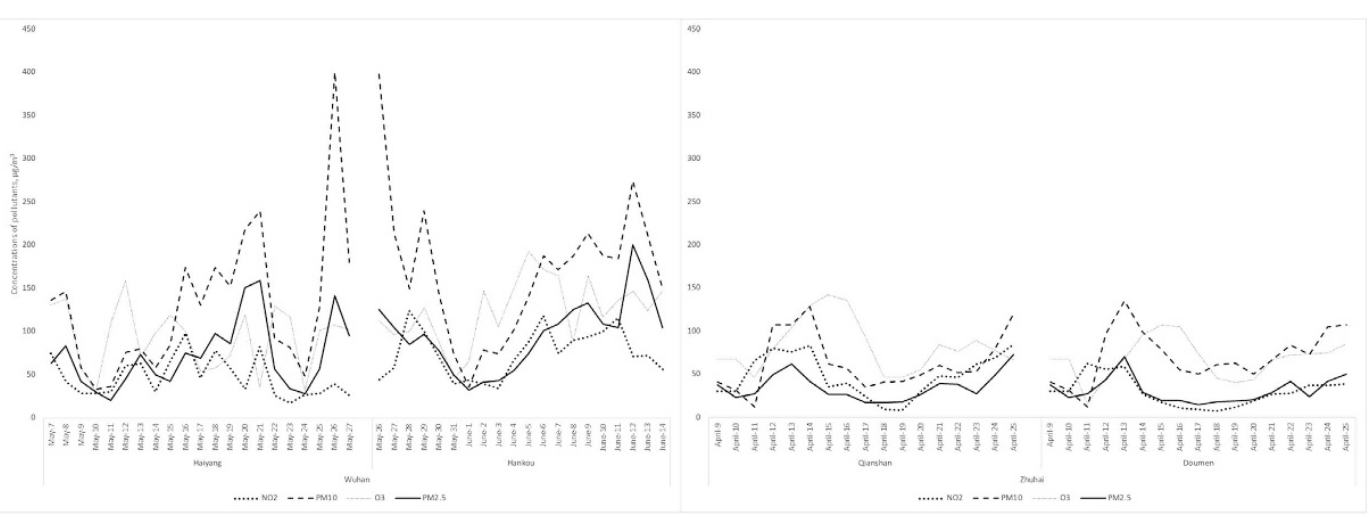

Figure 1. Distribution of ambient air pollutants in two cities during the preceding 0-7 days (Lag0-Lag7) before lung function test. The plotted values are the 24 -h averages of pollutant concentrations reported from the 4 monitoring stations in two cities.

\begin{tabular}{|l|c|c|c|c|c|c|c|c|c|c|c|c|c|}
\hline & \multicolumn{4}{|c|}{ Total (N=75) } & \multicolumn{4}{c|}{ Wuhan (N=41) } & \multicolumn{4}{c|}{ Zhuhai (N=34) } \\
\cline { 2 - 15 } & Mean & SD & Range & Median & Mean & SD & Range & Median & Mean & SD & Range & Median \\
\hline $\mathrm{NO}_{2}, \mu \mathrm{g} / \mathrm{m}^{3}$ & 50.73 & 28.40 & 7.75 to 124 & 43.2 & 60.36 & 29.04 & 17.6 to 124 & 57.6 & 39.13 & 23.08 & 7.75 to 84.50 & 32.5 \\
\hline $\mathrm{PM}_{10}, \mu \mathrm{g} / \mathrm{m}^{3}$ & 112.32 & 78.06 & 12.3 to 400.4 & 84.0 & 149.76 & 85.19 & 33 to 400.4 & 146.0 & 67.17 & 32.04 & 12.30 to 134.75 & 60.63 \\
\hline $\mathrm{O}_{3}, \mu \mathrm{g} / \mathrm{m}^{3}$ & 93.20 & 38.67 & 16.0 to 193 & 89.0 & 108.05 & 40.31 & 30 to 193 & 110.8 & 75.30 & 27.91 & 16.0 to 142.50 & 72.8 \\
\hline $\mathrm{PM}_{2.5}, \mu \mathrm{g} / \mathrm{m}^{3}$ & 60.71 & 41.25 & 15.0 to 200 & 45.4 & 83.57 & 42.19 & 20.3 to 200 & 77.4 & 33.14 & 15.03 & 15.0 to 72.50 & 27.1 \\
\hline
\end{tabular}

Table 2. Distribution of all pollutants (daily average of ambient air pollutants). Abbreviations: $\mathrm{NO}_{2}$, nitrogen dioxide; $\mathrm{O}_{3}$, ozone; $\mathrm{PM}_{10}$, particulate matter $<1 \mu \mathrm{m}$ in diameter; $\mathrm{PM}_{2.5}$, particulate matter $<2.5 \mu \mathrm{m}$ in diameter; SD, standard deviation.

\begin{tabular}{|l|c|c|c|c|c|c|c|c|c|c|c|c|}
\hline \multirow{2}{*}{ Air pollutants } & \multicolumn{4}{|c|}{ Total (N=75) } & \multicolumn{4}{c|}{ Wuhan (N=41) } & \multicolumn{4}{c|}{ Zhuhai (N=34) } \\
\cline { 2 - 15 } & $\mathbf{N O}_{2}$ & $\mathbf{P M}_{10}$ & $\mathbf{O}_{3}$ & $\mathbf{P M}_{2.5}$ & $\mathbf{N O}_{2}$ & $\mathbf{P M}_{10}$ & $\mathbf{O}_{3}$ & $\mathbf{P M}_{2.5}$ & $\mathbf{N O}_{2}$ & $\mathbf{P M}_{10}$ & $\mathbf{O}_{3}$ & $\mathbf{P M}_{2.5}$ \\
\hline $\mathrm{NO}_{2}, \mu \mathrm{g} / \mathrm{m}^{3}$ & 1 & & & & 1 & & & & 1 & & & \\
\hline $\mathrm{PM}_{10}, \mu \mathrm{g} / \mathrm{m}^{3}$ & $0.59^{\star}$ & 1 & & & $0.53^{\star}$ & 1 & & & $0.37^{\dagger}$ & 1 & & \\
\hline $\mathrm{O}_{3}, \mu \mathrm{g} / \mathrm{m}^{3}$ & $0.37^{\star}$ & $0.51^{\star}$ & 1 & & 0.31 & 0.28 & 1 & & 0.23 & $0.39^{\dagger}$ & 1 & \\
\hline $\mathrm{PM}_{2.5}, \mu \mathrm{g} / \mathrm{m}^{3}$ & $0.69^{\star}$ & $0.90^{\star}$ & $0.44^{\star}$ & 1 & $0.54^{\star}$ & $0.94^{*}$ & 0.25 & 1 & $0.80^{\star}$ & $0.64^{\star}$ & 0.21 & 1 \\
\hline
\end{tabular}

Table 3. Spearman correlation coefficients among air pollutants. Abbreviations: $\mathrm{NO}_{2}$, nitrogen dioxide; $\mathrm{O}_{3}$, ozone; $\mathrm{PM}_{10}$, particulate matter $<10 \mu \mathrm{m}$ in diameter; $\mathrm{PM}_{2.5}$, particulate matter $<2.5 \mu \mathrm{m}$ in diameter. ${ }^{*} p<0.01$; ${ }^{\dagger} p<0.05$.

We observed that each IQR-increase of $\mathrm{NO}_{2}, \mathrm{PM}_{10}$ or $\mathrm{PM}_{2.5}$ was significantly associated with a 81.04, 85.27 or $87.18 \mathrm{ml}$ decline of FVC in the 8-day moving average of exposures (Lag07).

We examined the effects of air pollutants (Lag07) on lung function for different groups (Table 4). Age was a potential modifier in association between $\mathrm{O}_{3}$ exposure and FVC decline ( $p$ values for interaction $=0.04$ ). The adverse effect of $\mathrm{O}_{3}$ on lung function was stronger in participants aged more than 45 year-old than those aged under 45 years old.

Figure 3 provides the associations between the moving averages of the 4 air pollutant exposures and lung function levels among non-smoking females living in Wuhan. Short-term exposures of $\mathrm{NO}_{2}\left(\operatorname{Lag} 02\right.$-Lag07), $\mathrm{PM}_{10}$ (Lag01-Lag07), $\mathrm{O}_{3}(\mathrm{Lag} 0-\mathrm{Lag} 07)$, and $\mathrm{PM}_{2.5}(\mathrm{Lag} 0-\mathrm{Lag} 07)$ were significantly associated with $\mathrm{FVC}$ reduction. $\mathrm{NO}_{2}$ (Lag06 and Lag07), $\mathrm{PM}_{10}$ (Lag06-Lag07), $\mathrm{O}_{3}$ (Lag0, Lag01 and Lag07), and $\mathrm{PM}_{2.5}$ (Lag03-Lag07) were significantly associated with reduced $\mathrm{FEV}_{1}$. The associations were stronger for longer moving averages of exposures. In Zhuhai, $\mathrm{PM}_{10}$ (Lag03-Lag05) and $\mathrm{O}_{3}$ exposure (Lag01-Lag03) was significantly associated with FVC reduction, while $\mathrm{PM}_{10}$ (Lag03-Lag05), $\mathrm{O}_{3}$ (Lag0-Lag03), and $\mathrm{PM}_{2.5}$ (Lag04-Lag06) exposures were significantly associated with $\mathrm{FEV}_{1}$ reduction, and the associations became weak or absent for longer moving averages of exposures (Fig. 4).

\section{Discussion}

In this study, we found that $\mathrm{NO}_{2}(\mathrm{Lag} 07), \mathrm{PM}_{10}$ (Lag03-Lag07), and $\mathrm{PM}_{2.5}$ (Lag02-Lag07) were significantly associated with FVC reduction among female non-smokers. We also found that air pollution levels may modify the short-term effects of air pollutant exposures on lung function. The adverse effects of high air pollutant levels on lung function could cumulate over several days, while the effects of low air pollutant levels could appear on the same day as exposure, and weak or absent for longer moving averages of exposures. 


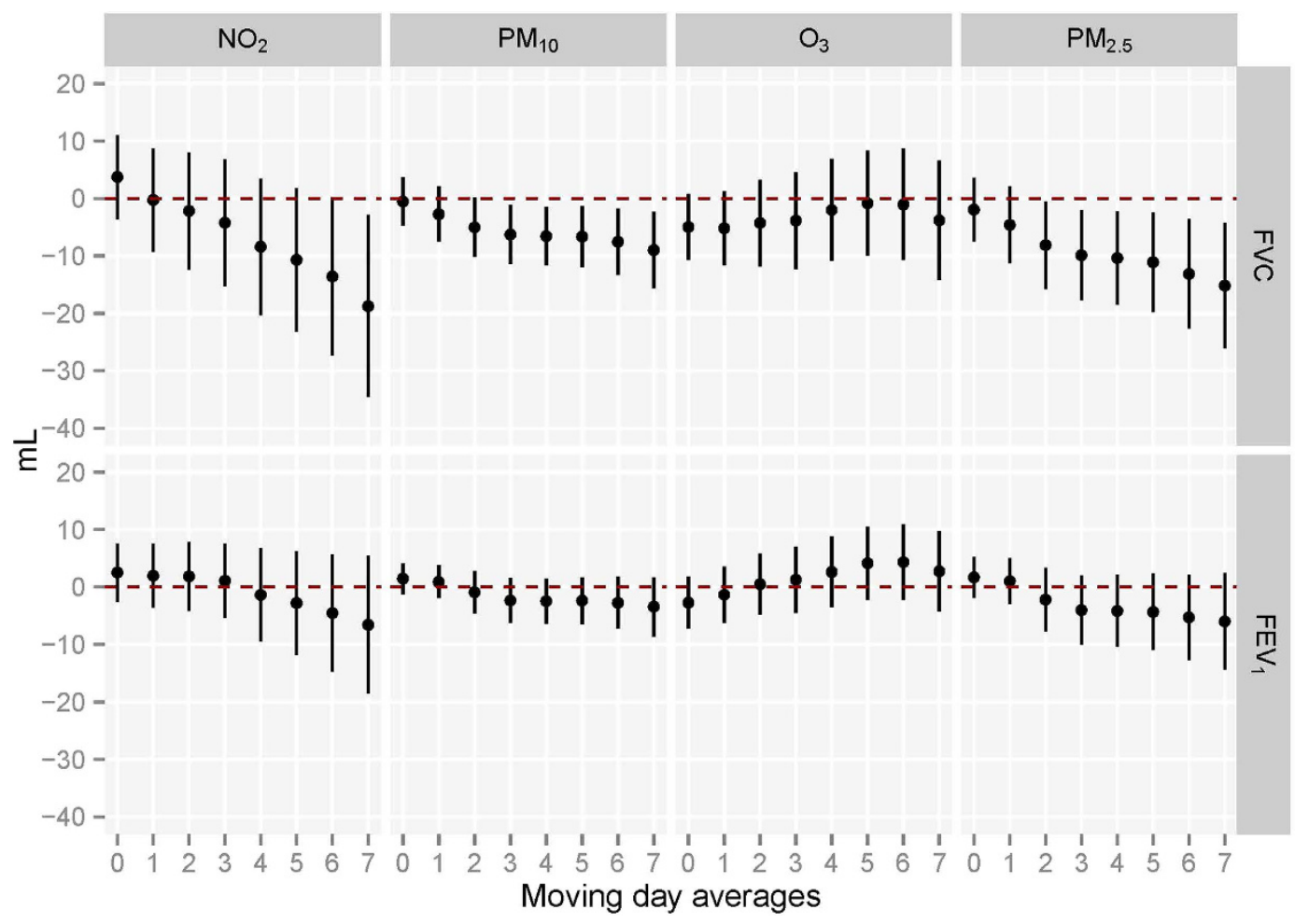

Figure 2. Associations between moving averages of air pollutant exposures before test and lung function $(\mathrm{N}=1, \mathbf{6 9 4})$. Abbreviations: $\mathrm{FVC}$, forced vital capacity; $\mathrm{FEV}_{1}$, forced expiratory volume in 1 second. The linear mixed models included city (Wuhan and Zhuhai) as a random effect and adjusted for age, height, body mass index, passive smoking status, asthma, heart diseases, physical activities and cooking meals at home. Associations with lung function are scaled per $10 \mu \mathrm{g} / \mathrm{m}^{3}$ increase in all the pollutants concentrations for each moving average.

We noted that the associations of air pollutant exposures with lung function alterations were different between two cities at different pollutant levels. One possible reason for the different changes of lung function between Wuhan and Zhuhai might be that air pollutant concentrations in two cities are various. In China, an individual score (IAQI) is assigned to the level of each pollutants and the final air quality index (AQI) is the highest of those 6 scores. Air quality is divided into 6 categories according to the AQI level, including 0 to 50,51 to 100,101 to 150 , 151 to 200,201 to 300 , and more than 300, which represents excellent, good, lightly, moderately, heavily or severely polluted level of air pollution, respectively. According to the report from China's Ministry of Environmental Protection, in 2014, the number of days at different polluted levels (lightly, moderately, heavily or severely polluted) in Wuhan was 183 (50.1\%), while only 44 (12.1\%) in Zhuhai annually. Compared with Wuhan, the air pollutant concentrations in Zhuhai city are much lower and closer to those in some developed countries. Similarly, the associations in Zhuhai were consistent to the results of most studies in developed countries at low pollutant levels. A cohort study in the US reported acute adverse effects of $\mathrm{PM}_{2.5}, \mathrm{NO}_{2}$ and $\mathrm{O}_{3}$ (Lag01-Lag02) were associated with $\mathrm{FEV}_{1}$ and $\mathrm{FVC}$ decline ${ }^{3}$. A Swiss cross-sectional study also reported acute exposure (Lag0 and Lag03) to total suspended particulate were significantly associated with decreased FVC and $\mathrm{FEV}_{1}$ among non-smokers ${ }^{17}$. In contrast, only a few studies examined the associations between relatively high air pollutant and lung function. A Brazil study at high air pollutant levels $\left(\mathrm{PM}_{10}: 84.68 \mu \mathrm{g} / \mathrm{m}^{3}, \mathrm{NO}_{2}: 92.50 \mu \mathrm{g} / \mathrm{m}^{3}\right.$ and $\left.\mathrm{O}_{3}: 81.08 \mu \mathrm{g} / \mathrm{m}^{3}\right)$ reported that increased moving averages of $\mathrm{PM}_{10}(\mathrm{Lag} 01-\mathrm{Lag} 02)$ exposure were associated with lung function decline among school children. They also observed a cumulative adverse effects on lung function ${ }^{16}$. Nonetheless, the Brazil study did not detail the associations for more than 3 days moving averages of pollutant exposure. In this study, we confirmed and extended the results of the Brazil study by investigating up to 7 days moving averages of exposure. We found that high levels of $\mathrm{PM}_{10}, \mathrm{NO}_{2}, \mathrm{O}_{3}$ and $\mathrm{PM}_{2.5}$ might affect lung function on the same day as the exposure and cumulate almost a week. It was hypothesized that compensatory protective mechanisms were responsible for lung function recovery after low concentrations of air pollutant exposures ${ }^{22}$. Whereas several day cumulative exposures to high levels of air pollutants may cause lung function decrement beyond compensatory and even the impairment in lung, which is likely difficult to relieve or dismiss.

The component of air pollution is another possible reason for the different effects on lung function in two cities. During the study period, the primary pollutants in Wuhan and Zhuhai were $\mathrm{PM}$ and $\mathrm{O}_{3}$, respectively. As a secondary pollutant, ground-level $\mathrm{O}_{3}$ is generated when emissions like nitrogen oxide and volatile organic compounds produced by cars, factories and other sources baked in the hot summer sun. Zhuhai is at downwind position of Guangzhou and Dongguan city, where the air creates high levels of $\mathrm{O}_{3}$, especially in summer. 


\begin{tabular}{|c|c|c|c|c|c|}
\hline \multirow{2}{*}{$\begin{array}{l}\text { Lung function } \\
\text { parameters }\end{array}$} & \multirow[b]{2}{*}{ Stratified characteristics } & \multicolumn{4}{|c|}{ Estimated change in Lung function* } \\
\hline & & $\mathrm{NO}_{2}$ & $\mathbf{P M}_{10}$ & $\mathrm{O}_{3}$ & $\mathbf{P M}_{2.5}$ \\
\hline \multicolumn{6}{|l|}{ FVC } \\
\hline & \multicolumn{5}{|l|}{ Age } \\
\hline & $<45$ & $-44.78(-92.35,2.80)$ & $-8.58(-25.29,8.13)$ & $-16.62(-45.46,12.21)$ & $-15.61(-43.20,11.98)$ \\
\hline & $\geq 45$ & $-26.40(-42.17,-10.62)$ & $-11.95(-18.63,-5.27)$ & $-12.49(-23.01,-1.97)$ & $-20.59(-31.58,-9.60)$ \\
\hline & $p$ value for interaction & 0.23 & 0.69 & 0.04 & 0.66 \\
\hline & \multicolumn{5}{|l|}{ Body Mass Index } \\
\hline & $<24$ & $-22.42(-47.10,2.26)$ & $-14.95(-25.33,-4.57)$ & $1.14(-14.86,17.14)$ & $-24.48(-41.30,-7.66)$ \\
\hline & $\geq 24$ & $-26.06(-45.01,-7.11)$ & $-6.07(-13.88,1.74)$ & $-16.86(-29.34,-4.39)$ & $-10.91(-23.90,2.09)$ \\
\hline & $p$ value for interaction & 0.37 & 0.87 & 0.09 & 0.96 \\
\hline & \multicolumn{5}{|l|}{ Cooking } \\
\hline & Yes & $-35.53(-51.19,-19.87)$ & $-13.23(-19.76,-6.71)$ & $-16.85(-27.16,-6.54)$ & $-23.15(-33.95,-12.35)$ \\
\hline & No & $4.77(-25.10,34.63)$ & $1.65(-11.99,15.28)$ & $0.31(-22.67,23.29)$ & $3.85(-16.37,24.07)$ \\
\hline & $p$ value for interaction & 0.94 & 0.76 & 0.82 & 0.80 \\
\hline & \multicolumn{5}{|l|}{ Exercise } \\
\hline & Yes & $-31.40(-51.24,-11.56)$ & $-12.65(-21.14,-4.17)$ & $-14.09(-27.16,-1.02)$ & $-21.02(-34.94,-7.11)$ \\
\hline & No & $-15.23(-38.82,8.36)$ & $-5.85(-15.42,3.71)$ & $-7.75(-23.23,7.73)$ & $-11.60(-27.38,4.18)$ \\
\hline & $p$ value for interaction & 0.31 & 0.18 & 0.79 & 0.24 \\
\hline \multicolumn{6}{|l|}{$\mathrm{FEV}_{1}$} \\
\hline & \multicolumn{5}{|l|}{ Age } \\
\hline & $<45$ & $-30.12(-68.79,8.56)$ & $-8.55(-22.02,4.91)$ & $-3.33(-26.46,19.79)$ & $-17.94(-40.38,4.51)$ \\
\hline & $\geq 45$ & $-12.11(-24.47,0.24)$ & $-4.39(-9.57,0.80)$ & $-3.11(-10.69,4.46)$ & $-7.74(-16.28,0.80)$ \\
\hline & $p$ value for interaction & 0.90 & 0.26 & 0.25 & 0.25 \\
\hline & \multicolumn{5}{|l|}{ Body Mass Index } \\
\hline & $<24$ & $-4.51(-17.76,8.75)$ & $-4.86(-11.68,1.96)$ & $3.45(-6.7,13.6)$ & $-7.88(-18.97,3.21)$ \\
\hline & $\geq 24$ & $-14.18(-29.93,1.58)$ & $-2.11(-8.35,4.13)$ & $-8.04(-18.46,2.39)$ & $-4.72(-15.06,5.62)$ \\
\hline & $p$ value for interaction & 0.84 & 0.64 & 0.40 & 0.78 \\
\hline & \multicolumn{5}{|l|}{ Cooking } \\
\hline & Yes & $-21.51(-34.44,-8.58)$ & $-7.24(-12.59,-1.89)$ & $-9.04(-17.44,-0.63)$ & $-13.15(-22.03,-4.28)$ \\
\hline & No & $-11.19(-35.66,13.29)$ & $-4.36(-15.54,6.82)$ & $-3.53(-22.16,15.1)$ & $-6.23(-22.81,10.35)$ \\
\hline & $p$ value for interaction & 0.99 & 0.77 & 0.99 & 0.79 \\
\hline & \multicolumn{5}{|l|}{ Exercise } \\
\hline & Yes & $-18.09(-32.96,-3.22)$ & $-5.12(-10.51,0.27)$ & $-6.94(-15.6,1.72)$ & $-9.10(-18.56,0.36)$ \\
\hline & No & $0.25(-17.31,17.82)$ & $-0.32(-7.71,7.08)$ & $2.93(-8.8,14.66)$ & $-2.15(-14.24,9.94)$ \\
\hline & $p$ value for interaction & 0.20 & 0.18 & 0.55 & 0.22 \\
\hline
\end{tabular}

Table 4. The estimated changes in FVC and $\mathrm{FEV}_{1}$ associated with $10 \mu \mathrm{g} / \mathrm{m}^{3}$ increase in all the pollutants at lag07 in different groups $(\mathbf{N}=\mathbf{1 , 6 9 4})$. Abbreviations: $\mathrm{FVC}$, forced vital capacity; $\mathrm{FEV}_{1}$, forced expiratory volume in 1 second; $\mathrm{NO}_{2}$, nitrogen dioxide; $\mathrm{O}_{3}$, ozone; $\mathrm{PM}_{10}$, particulate matter $<10 \mu \mathrm{m}$ in diameter; $\mathrm{PM}_{2.5}$, particulate matter $<2.5 \mu \mathrm{m}$ in diameter. ${ }^{\star}$ Estimated change is calculated by linear regression models with adjustment for age, height, body mass index, passive smoking status, asthma, heart diseases, physical activities and cooking. Associations with lung function are scaled per $10 \mu \mathrm{g} / \mathrm{m}^{3}$ increase in all the pollutants concentrations for each moving average.

In this study, we also noted that current and previous day exposure of $\mathrm{O}_{3}$ was associated with both $\mathrm{FVC}$ and $\mathrm{FEV}_{1}$, indicating that adverse effects of $\mathrm{O}_{3}$ exposure on lung function occurs acutely. Animal evidences demonstrated that $\mathrm{O}_{3}$ exposure prime innate immunity and up-regulate expression of injury repair genes in the lung. Meanwhile, $\mathrm{O}_{3}$ can also stimulate airway neural receptors like airways $\mathrm{C}$-fibers and transmit to the central nervous system through afferent vagal nerve pathways ${ }^{23,24}$, resulting in some airway narrowing, neural inhibition of inhalation effort at high lung volumes.

Similar to other studies, we found that outdoor PM was associated with lung function reduction. PM can induce small airways constriction by stimulating endothelia release and activating direct oxidant effects and inflammation ${ }^{25}$. Most studies suggest that PM can penetrates into and retains in the walls of small airways leading to generating free radicals and triggering intracellular oxidative stress. Free radicals can further recruit inflammatory cells and generate inflammatory mediators and then cause airway wall remodeling and lung tissue damage ${ }^{26-30}$. We also observed $\mathrm{NO}_{2}$ exposure was associated with lung function decline, similar to the results of previous studies ${ }^{12,31}$. Possible reasons for the observed reductions in spirometry parameters may be that the nitrate or nitrite formed from $\mathrm{NO}_{2}$ directly irritates or corrodes lung epithelial cells or tissue, increases the permeability of alveolar and capillary, leading to pulmonary edema. Inhalation of $\mathrm{NO}_{2}$ can also cause lung injury by inducing inflammation response and the imbalance of Th1/Th2 differentiation, and activating the JAK-STAT pathways ${ }^{32,33}$. 


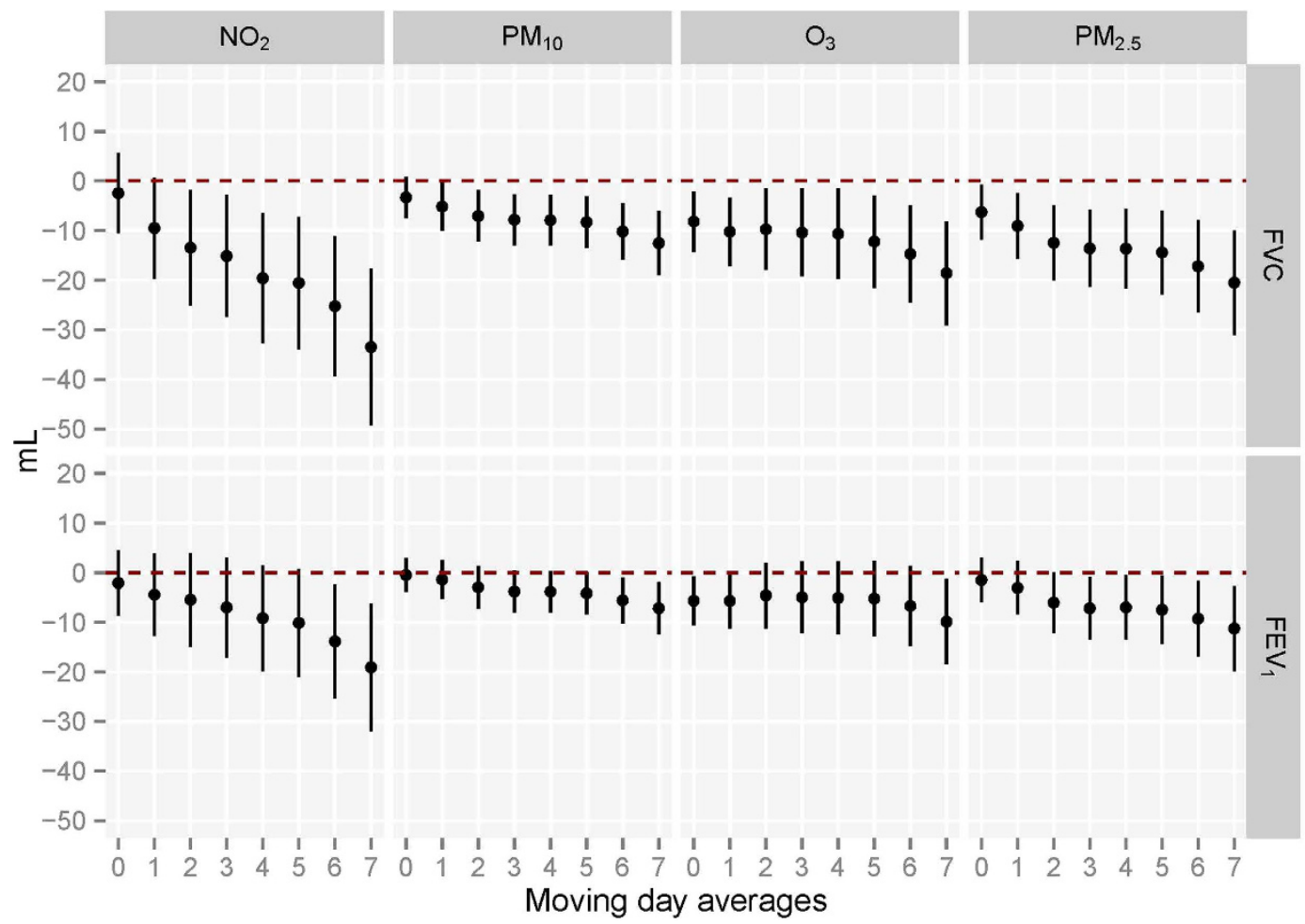

Figure 3. Associations between moving averages of air pollutants exposures before test and FVC and FEV with single pollutant models in Wuhan $(\mathbf{N}=\mathbf{1 , 1 7 7})$. Abbreviations: $\mathrm{FVC}$, forced vital capacity; $\mathrm{FEV}_{1}$, forced expiratory volume in 1 second; $\mathrm{NO}_{2}$, nitrogen dioxide; $\mathrm{O}_{3}$, ozone; $\mathrm{PM}_{10}$, particulate matter $<10 \mu \mathrm{m}$ in diameter; $\mathrm{PM}_{2.5}$, particulate matter $<2.5 \mu \mathrm{m}$ in diameter. ${ }^{\star}$ Estimated change is calculated by linear regression models with adjustment for age, height, body mass index, passive smoking status, asthma, heart diseases, physical activities and cooking meals at home. Associations with lung function are scaled per $10 \mu \mathrm{g} / \mathrm{m}^{3}$ increase in all the pollutants concentrations for each moving average.

There are several strengths in this study. We chose two cities to investigate the short-term effects of outdoor air pollution on lung function at remarkably different air quality levels. In addition, we analyzed associations between air pollutant exposures and lung function among restricted samples, which can help avoid being confounded sex and cigarette smoking. Finally, we used the same methods for data collection in two different cities to avoid measurement biases, and all the results were adjusted for many potential confounders and predictors of lung function.

One limitation of our study is that we ignored indoor air pollution. The effects on lung function resulted from both outdoor and indoor air pollution exposures. Using outdoor air pollution as a proxy as the 24 hour exposure may cause exposure misclassification. However, previous studies suggested that outdoor air pollution measurements may be used as a surrogate for individual level exposures in most populations. Moreover, we did not collect data on temperature or humidity, and control them as potential confounders, though the two factors did not vary dramatically within each city during study period. It is also clear that both long-term and short-term effects of air pollution on lung function exist, but we are unable to study the long-term effect of air pollution and lung function because the air pollutant monitoring data were unavailable before 2013. Therefore we are unable to distinguish short-term and long-term effect of air pollution exposure on lung function in the study. Further studies are needed to explore the clearer separations of short-term and long-term effects of air pollution on lung function. In conclusion, female non-smokers may experience adverse effects on the respiratory system from air pollutants, and higher level may lead to continuous damage to the lung. To protect lung function in heavy polluted area, it is necessary for female non-smokers to lower indoor air pollution, take activities, and use personal protective equipment.

\section{Methods}

Study Population. The study population is from the Wuhan-Zhuhai cohort ${ }^{34}$, which was established between April 2011 and June 2012, and enrolled 4,812 residents aged 18 to 80 years who had lived in Wuhan $(\mathrm{N}=3,053)$ or Zhuhai city $(\mathrm{N}=1,759)$ for more than five years. Three years later, the cohort participants were followed up for personal information update and the second physical health examination. Due to lack of data on air pollutants during 2011 to 2012, we only included the lung function test data from the second physical health examination between 2014 and 2015. A face-to-face interview was conducted for each participant by trained investigators. Data on health and lifestyle questionnaires covered information on demographic characteristics, occupational hazards exposure, smoking history, passive smoking history, alcohol consumption, physical activity, 


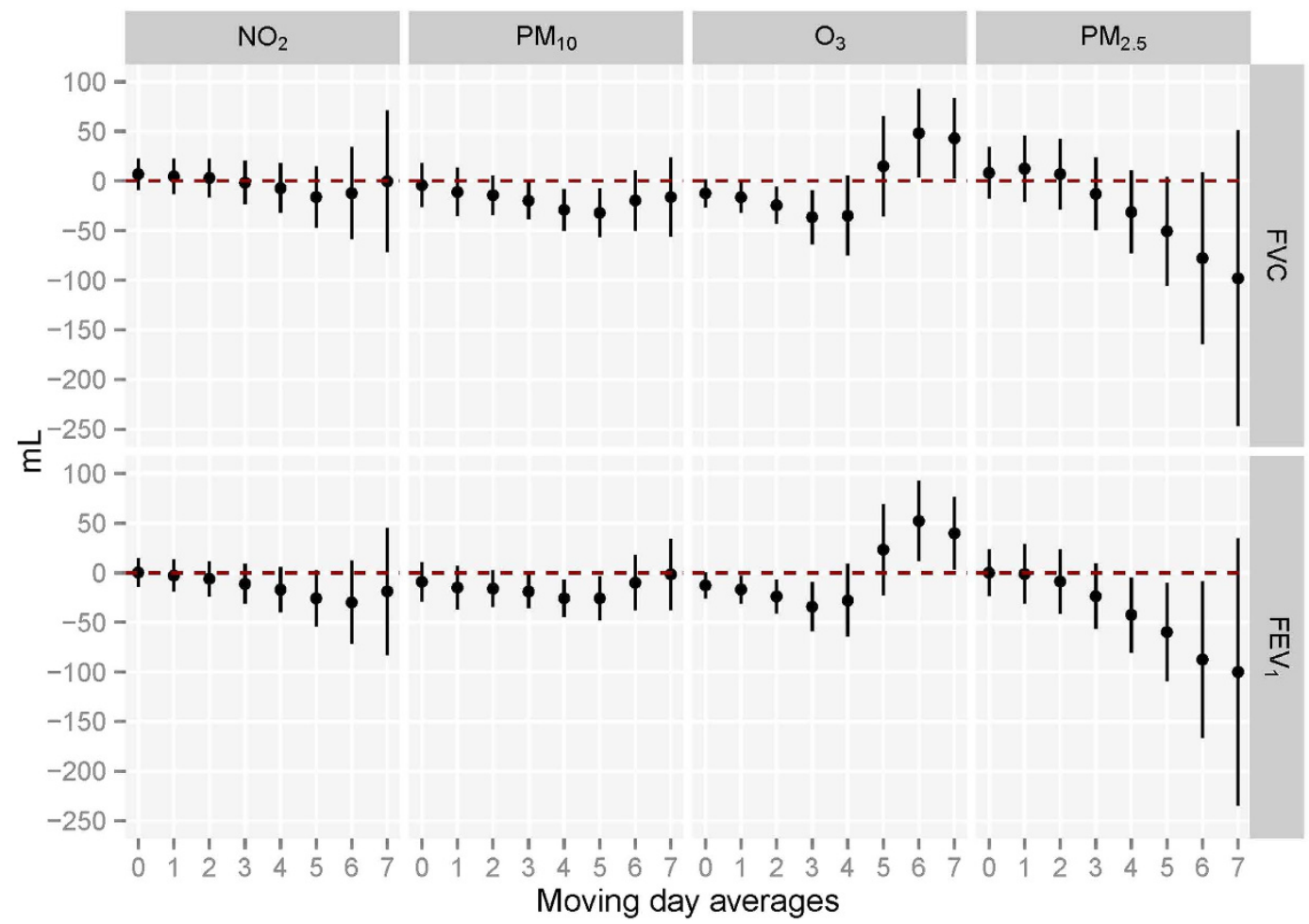

Figure 4. Associations between moving averages of air pollutants exposures before test and FVC and FEV with single pollutant models and Zhuhai $(\mathbf{N}=\mathbf{5 1 7})$. Abbreviations: $F V C$, forced vital capacity; $\mathrm{FEV}_{1}$, forced expiratory volume in 1 second; $\mathrm{NO}_{2}$, nitrogen dioxide; $\mathrm{O}_{3}$, ozone; $\mathrm{PM}_{10}$, particulate matter $<10 \mu \mathrm{m}$ in diameter; $\mathrm{PM}_{2.5}$, particulate matter $<2.5 \mu \mathrm{m}$ in diameter. ${ }^{\star}$ Estimated change is calculated by linear regression models with adjustment for age, height, body mass index, passive smoking status, asthma, heart diseases, physical activities and cooking meals at home. Associations with lung function are scaled per $10 \mu \mathrm{g} / \mathrm{m}^{3}$ increase in all the pollutants concentrations for each moving average.

and cooking were collected in the study. After interview, a physical examination including lung function test was conducted. Residents who refused to attend clinic visits, or had severe illnesses were excluded from the study. By excluding 877 males and 653 cigarette smokers, 1,694 female non-smokers were included in this analysis.

Ethics Statement. The research protocol was approved by the institutional review boards of Tongji Medical College, Huazhong University of Science and Technology, P.R. China. The methods were carried out in accordance with the relevant guidelines. All participants enrolled in this study gave written informed consent for participation.

Lung function test. Lung function test was performed by specialists using electronic spirometers (Chestgraph HI-101, CHEST Ltd., Tokyo, Japan). Each participant was done in a sitting position with a nose clip after at least 5 minutes of normal breathing, and advised not to smoke for at least one hour or not to eat a large meal for two hours before the test. False teeth should be left in place unless they prevented the participant from forming an effective seal around the mouth piece. Three acceptable volume-time curves of forced vital capacity (FVC) or forced expiratory volume in one second $\left(\mathrm{FEV}_{1}\right)$ were obtained and recorded in accordance with the American Thoracic Society (ATS) recommendations ${ }^{35}$.

Environmental air pollution exposure assessment. Daily air pollution data on $\mathrm{NO}_{2}, \mathrm{PM}_{10}, \mathrm{O}_{3}$, and $\mathrm{PM}_{2.5}$ concentrations in Wuhan and Zhuhai were obtained from the National Real-Time Air Quality Monitoring Data Publishing Platform developed by China National Environmental Monitoring Center (CNEMC). There were 10 and 4 available fixed-sit air quality monitoring stations in Wuhan and Zhuhai, respectively. All the monitoring stations were located away from traffic, industrial sources, buildings or residential sources of emissions from the burning coal waste or oil, according to technical guidelines of the Chinese government ${ }^{36}$. Air pollutant levels for the four study communities ( 2 in Wuhan, and 2 in Zhuhai) were assessed by using data from the nearest monitoring stations. For each study community, average daily values for each pollutant were calculated using its hourly ambient air concentration. The analytical methods and instruments for air pollutants were conducted according to the ambient air quality standards in China. The concentration of $\mathrm{PM}_{2.5}$ or $\mathrm{PM}_{10}$ was measured by using the micro oscillating balance method and/or the $\beta$ absorption method. $\mathrm{NO}_{2}$ and $\mathrm{O}_{3}$ were measured by using the chemiluminescence method (and/or differential optical absorption spectroscopy) and ultraviolet fluorescence method (and/or differential optical absorption spectroscopy) respectively. 
Statistical analysis. Daily average air pollutant concentrations were matched with lung function data for each participant before analysis. Spearman correlation coefficient was used to evaluate the bivariate associations between air pollutants during the study period. Associations between exposure variables and lung function were assessed using linear mixed models by including city (Wuhan/Zhuhai) as a random effect. The cumulative effects were examined by modelling moving average concentrations during the preceding 0-7 days (Lag0-Lag07) before lung function test. For example, Lag01 represented a 2-day moving average exposure, which was calculated as the average concentrations of the current and the previous day. Potential confounders were adjusted in all linear models, including age, height, body mass index (BMI), heart disease, asthma, occupational hazard exposure, passive smoking status, drinking status, physical activity, and cooking. Associations were quantified by using estimated changes and $95 \%$ confidence intervals (CIs) of lung function (FVC and $\mathrm{FEV}_{1}$ ) levels by each $10 \mu \mathrm{g} / \mathrm{m}^{3}$ increase of air pollutant concentrations.

We also stratified the analyses in different groups including age groups ( $<45$ and $\geq 45$ years old), BMI groups $\left(<24\right.$ and $\geq 24 \mathrm{~kg} / \mathrm{m}^{3}$ ), regular physical activity groups (yes and no) and cooking groups (yes and no) by linear mixed models. Effect modification of each covariate in association of each pollutant and lung function was calculated by including an interaction term of each pollutant multiplied by the covariate in the linear mixed model.

We further tested whether association between each air pollutant exposure and lung function $\left(\mathrm{FVC}\right.$ and $\left.\mathrm{FEV}_{1}\right)$ differed with two cities at different polluted levels by using linear regression. All statistical analyses were performed using the SAS 9.3 software. The statistical significant level was defined as $p<0.05$ (2-sided).

\section{References}

1. Ministry of Environmental Protection of the People's Republic of China. Report on the State of the Environment of China. Report on the State of the Environment of China. http://jcs.mep.gov.cn/hjzl/zkgb/2014zkgb/201506/t20150608_303142.htm (2014).

2. World Health Organization. Air quality guidelines - global update 2005. http://www.who.int/phe/health_topics/outdoorair/ outdoorair_aqg/en/ (2005).

3. Rice, M. B. et al. Short-term exposure to air pollution and lung function in the Framingham Heart Study. American journal of respiratory and critical care medicine 188, 1351-1357, doi: 10.1164/rccm.201308-1414OC (2013).

4. Cakmak, S., Dales, R., Leech, J. \& Liu, L. The influence of air pollution on cardiovascular and pulmonary function and exercise capacity: Canadian Health Measures Survey (CHMS). Environmental research 111, 1309-1312, doi: 10.1016/j.envres.2011.09.016 (2011).

5. Pope, C. A. 3rd \& Kanner, R. E. Acute effects of PM10 pollution on pulmonary function of smokers with mild to moderate chronic obstructive pulmonary disease. The American review of respiratory disease 147, 1336-1340, doi: 10.1164/ajrccm/147.6_Pt_1.1336 (1993).

6. Health effects of outdoor air pollution. Committee of the Environmental and Occupational Health Assembly of the American Thoracic Society. American journal of respiratory and critical care medicine 153, 3-50, doi: 10.1164/ajrccm.153.1.8542133 (1996).

7. Ko, F. W. \& Hui, D. S. Air pollution and chronic obstructive pulmonary disease. Respirology 17, 395-401, doi: 10.1111/j.1440-1843. 2011.02112.x (2012).

8. Young, M. T. et al. Ambient air pollution exposure and incident adult asthma in a nationwide cohort of US women. American journal of respiratory and critical care medicine 190, 914-921, doi: 10.1164/rccm.201403-0525OC (2014).

9. Liu, L. \& Zhang, J. Ambient air pollution and children's lung function in China. Environment international 35, 178-186, doi: 10.1016/j.envint.2008.06.004 (2009).

10. Baccarelli, A. A. et al. Air pollution exposure and lung function in highly exposed subjects in Beijing, China: a repeated-measure study. Particle and fibre toxicology 11, 51, doi: 10.1186/s12989-014-0051-7 (2014).

11. Chen, P. C. et al. Short-term effect of ozone on the pulmonary function of children in primary school. Environmental health perspectives 107, 921-925 (1999).

12. Shepherd, M. A., Haynatzki, G., Rautiainen, R. \& Achutan, C. Estimates of community exposure and health risk to sulfur dioxide from power plant emissions using short-term mobile and stationary ambient air monitoring. Journal of the Air \& Waste Management Association 65, 1239-1246, doi: 10.1080/10962247.2015.1077174 (2015).

13. Chang, Y. K. et al. The short-term effects of air pollution on adolescent lung function in Taiwan. Chemosphere 87, 26-30, doi: 10.1016/j.chemosphere.2011.11.048 (2012).

14. Zhang, Y. et al. Short-Term Effects of Fine Particulate Matter and Temperature on Lung Function among Healthy College Students in Wuhan, China. International journal of environmental research and public health 12, 7777-7793, doi: 10.3390/ijerph120707777 (2015).

15. Li, J. Y. et al. [The short-term effects of particulate matter on lung function of college students in autumn and winter in Wuhan]. Zhonghua yu fang yi xue za zhi [Chinese journal of preventive medicine] 47, 155-159 (2013).

16. Castro, H. A. et al. Effect of air pollution on lung function in schoolchildren in Rio de Janeiro, Brazil. Revista de saude publica 43, 26-34 (2009).

17. Schindler, C. et al. Short-term variation in air pollution and in average lung function among never-smokers. The Swiss Study on Air Pollution and Lung Diseases in Adults (SAPALDIA). American journal of respiratory and critical care medicine 163, 356-361, doi: 10.1164/ajrccm.163.2.9911116 (2001).

18. van der Vaart, H., Postma, D. S., Timens, W. \& ten Hacken, N. H. Acute effects of cigarette smoke on inflammation and oxidative stress: a review. Thorax 59, 713-721, doi: 10.1136/thx.2003.012468 (2004).

19. Paulose-Ram, R., Tilert, T., Dillon, C. F. \& Brody, D. J. Cigarette smoking and lung obstruction among adults aged 40-79: United States, 2007-2012. NCHS data brief, 1-8 (2015).

20. Fischer, P. B. B. \& Biersteker, K. Effects of indoor exposure to nitrogen dioxide on pulmonary function of women living in urban and rural areas. Environment international 15, 375-381 (1989).

21. Chandrasekharan Nair Kesavachandran, V. B., Pangtey, B. S., Kamal, R., Singh, A. \& Srivastava, A. K. Gender Disparity in Lung Function Abnormalities among a Population Exposed to Particulate Matter Concentration in Ambient Air in the National Capital Region, India. Journal of Health and Pollution 5, 47-60 (2015).

22. Villarreal-Calderon, R. et al. Urban air pollution produces up-regulation of myocardial inflammatory genes and dark chocolate provides cardioprotection. Experimental and toxicologic pathology: official journal of the Gesellschaft fur Toxikologische Pathologie 64, 297-306, doi: 10.1016/j.etp.2010.09.002 (2012).

23. Oakes, J. L. et al. Ozone Enhances Pulmonary Innate Immune Response to a Toll-Like Receptor-2 Agonist. Am J Resp Cell Mol 48, 27-34, doi: DOI 10.1165/rcmb.2012-0187OC (2013)

24. Ho, C. Y. \& Lee, L. Y. Ozone enhances excitabilities of pulmonary C fibers to chemical and mechanical stimuli in anesthetized rats. J Appl Physiol 85, 1509-1515 (1998). 
25. Manzo, N. D. et al. Nitric oxide and superoxide mediate diesel particle effects in cytokine-treated mice and murine lung epithelial cells - implications for susceptibility to traffic-related air pollution. Part Fibre Toxicol 9, doi: Artn 43. Doi 10.1186/1743-8977-9-43 (2012).

26. Kelly, F. J. \& Fussell, J. C. Air pollution and airway disease. Clin Exp Allergy 41, 1059-1071, doi: DOI 10.1111/j.1365-2222.2011.03776.x (2011).

27. Rahman, I. \& MacNee, W. Oxidative stress and regulation of glutathione in lung inflammation. Eur Respir J 16, 534-554, doi: DOI 10.1034/j.1399-3003.2000.016003534.x (2000).

28. Stringer, B. \& Kobzik, L. Environmental particulate-mediated cytokine production in lung epithelial cells (A549): Role of preexisting inflammation and oxidant stress. J Toxicol Env Heal A 55, 31-44 (1998).

29. Churg, A., Brauer, M. \& del Carmen Avila-Casado, M. Fortoul, T. I. \& \& Wright, J. L. Chronic exposure to high levels of particulate air pollution and small airway remodeling. Environmental health perspectives 111, 714-718 (2003).

30. Dai, J., Xie, C., Vincent, R. \& Churg, A. Air pollution particles produce airway wall remodeling in rat tracheal explants. American journal of respiratory cell and molecular biology 29, 352-358, doi: 10.1165/rcmb.2002-0318OC (2003).

31. Lagorio, S. et al. Air pollution and lung function among susceptible adult subjects: a panel study. Environmental health: a global access science source 5, 11, doi: 10.1186/1476-069X-5-11 (2006).

32. Ji, X., Han, M., Yun, Y., Li, G. \& Sang, N. Acute nitrogen dioxide (NO2) exposure enhances airway inflammation via modulating Th1/Th2 differentiation and activating JAK-STAT pathway. Chemosphere 120, 722-728, doi: 10.1016/j.chemosphere.2014.10.039 (2015).

33. Walford, H. H. \& Doherty, T. A. STAT6 and lung inflammation. Jak-Stat 2, e25301, doi: 10.4161/jkst.25301 (2013).

34. Song, Y. et al. The Wuhan-Zhuhai (WHZH) cohort study of environmental air particulate matter and the pathogenesis of cardiopulmonary diseases: study design, methods and baseline characteristics of the cohort. BMC public health 14, 994, doi: 10.1186/1471-2458-14-994 (2014)

35. Standardization of Spirometry, 1994 Update. American Thoracic Society. American journal of respiratory and critical care medicine 152, 1107-1136, doi: 10.1164/ajrccm.152.3.7663792 (1995).

36. China National Environmental Monitoring Center. http://www.cnemc.cn/publish/totalWebSite/news/news_38841.html (2013).

\section{Acknowledgements}

We thank the study participants from Wuhan and Zhuhai city for their help. This work was supported by the key project of the National Natural Science Foundation of China (91543207); and the Health and Family Planning Commission of Hubei Province (WJ2015MA027).

\section{Author Contributions}

Y.Z. and Y.L. contributed to data collection, conducted data analysis, interpreted the results and wrote the manuscript. Y.S. and J.X. conducted data analysis, interpreted the results and revised the manuscript. X.C., B.Z. and T.S. helped to collect data and revised the manuscript. J.Y. and W.C. designed the study, collected the data, interpreted the results, and revised the manuscript. All authors reviewed the manuscript. W.C. is the guarantor of this work and has full access to all the data in the study and takes responsibility for the integrity of the data and the accuracy of the data analysis.

Additional Information

Supplementary information accompanies this paper at http://www.nature.com/srep

Competing financial interests: The authors declare no competing financial interests.

How to cite this article: Zhou, Y. et al. Short-term Effects of Outdoor Air Pollution on Lung Function among Female Non-smokers in China. Sci. Rep. 6, 34947; doi: 10.1038/srep34947 (2016).

(c) (i) This work is licensed under a Creative Commons Attribution 4.0 International License. The images or other third party material in this article are included in the article's Creative Commons license, unless indicated otherwise in the credit line; if the material is not included under the Creative Commons license, users will need to obtain permission from the license holder to reproduce the material. To view a copy of this license, visit http://creativecommons.org/licenses/by/4.0/

(c) The Author(s) 2016 